\title{
Quantifying Growth of Impervious Surface around the Hangzhou Bay, China
}

\author{
JIADAN LI \\ Institute of Agriculture Remote Sensing and Information \\ Technology, \\ College of Environment and Natural Resource, \\ Zhejiang University, \\ Hangzhou 310058, China \\ vaneljd@zju.edu.cn \\ KE WANG \\ Institute of Agriculture Remote Sensing and Information \\ Technology, \\ College of Environment and Natural Resource, \\ Zhejiang University, \\ Hangzhou 310058, China \\ kwang@zju.edu.cn
}

\begin{abstract}
This research employed impervious surface analysis to examine process of urban expansion around the Hangzhou Bay, China, by integrating Landsat data obtained over two different periods between 1987 and 2009(i.e., 1987, 2001 and 2009). The amount of impervious surface was quantified by Hyper Spectral Mixture Analysis (HSMA) for each year. We developed this technique to cope with mixed pixel problem in coastal region of this Bay. Results showed that south of the Hangzhou Bay witnessed rapid impervious surface expansion(non-industrial and industrial) in the period 2001to 2009 in comparison to the north part. We found that most urban lands were connected together through developing impervious surface. As a result, it generated a large area of impervious surface along coastal of the Hangzhou Bay. This situation may induce environmental problems in this Bay.

Index Terms: - HSMA, Impervious Surface, , Hangzhou Bay
\end{abstract}

\section{I .INTRODUCTION}

The eastern coastal cities of China are one the most important places not only in China but also in the world, because they have been selected as the engine of growth for Chinese economic development [1]. However, rapid urbanization and industrialization in these regions have triggered off tremendous land cover and land use changes [2]

Many valuable studies have been so far conducted by using remotely sensed data in order to examine impacts of rapid urban expansion in these regions [3],[4]. Much of the former researches have used conventional change detection techniques, but few studies employed impervious surface approaches for monitoring rapid urbanization. In fact, sustainable urban planning may be failed without information about impervious surface. This is because analyzing impervious surfaces will reveal three dimensions of urbanization and industrialization, namely, expansion of all kinds of urban lands, intra-class changes and environmental effects. Impervious surface not only includes built-up regions but also composes of all impermeable lands, for example,

\author{
AMIRREZA SHAHTAHMASSEBI \\ Institute of Agriculture Remote Sensing and Information \\ Technology, \\ College of Environment and Natural Resource, \\ Zhejiang University, \\ Hangzhou 310058, China \\ amir511@zju.edu.cn
}

highway, parking lots, etc [5]. Impervious surface can quantify sub-pixel changes while conventional techniques just extract inter-class conversion [6]. In addition, an increase in percent of impervious surface introduces a range of environmental problems such as reduce infiltration capacity of covered area, increasing temperature and leading sewage to natural streams [7].

The aim of this study is to identify pattern of urban changes by using impervious surface around the Hangzhou Bay, China, in two periods namely 1987-2001 and 20012009. However, since the study area was located along the coastal region, there was high percent of spectral similarity among bare lands, sedimentary regions and impervious surfaces, thus it made mixed-pixel problem. To reduce this effect, we developed a novel algorithm, which called Hyper Spectral Mixture Analysis (HSMA). The impervious surfaces of Hangzhou Bay were extracted by this algorithm.

\section{STUDY AREA}

The study area was located in the 6 counties around the Hangzhou bay, which included Cixi, Yoashi, Shengyou, Pinghu, Hayian and Haining(Figure 1). The total area of these counties is $5962 \mathrm{~km}^{2}$. Currently, all the cities and counties along Hangzhou Bay have established a batch of large-scale industrial clusters. These industries have occupied strong positions in China and abroad. Also urbanization level of its residents has reached to $50.87 \%$, which is more than $1 / 3$ above the national average. With respect to all these factors, Hangzhou Bay is witnessing a dramatic land cove and land use change. 


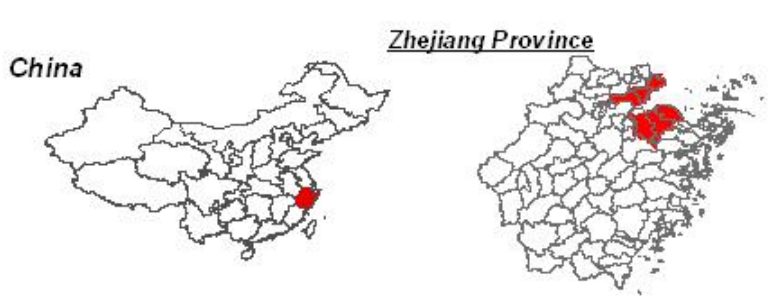

Hangzhou Bay-Study area

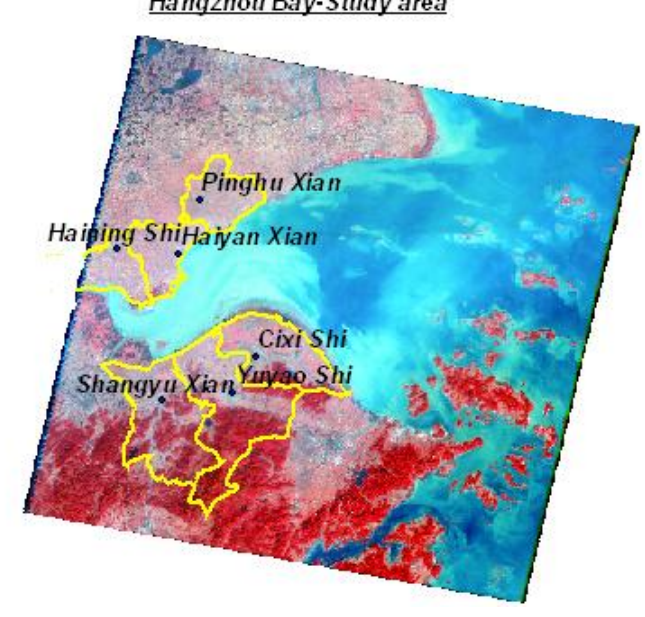

Figure 1 Hangzhou Bay

\section{METHODOLOGY}

\subsection{Data and preprocessing}

The predominantly cloud free images of Landsat imagery cover Hangzhou Bay were obtained for 1987(Landsat TM 5), 2001(Landsat ETM + 7) and 2009(Landsat TM 5). Radiometric calibration and atmospheric correction were applied to the Landsat images. The Digital Number (DN) of these images was first converted to the top-of-atmosphere radiance units using pre-launch calibration coefficients. Then the Dark Subtracted technique was applied to each band in order to reduce atmospheric effects.

\subsection{Estimating impervious surface by Hyper Spectral Mixture Analysis}

Spectral Mixture Analysis(SMA) was recognized as an effective method for many applications such as mapping impervious surface [8]. The SMA models each pixel as a linear sum of spectrally 'pure' endmembers [9]. The SMA formula is:
$\boldsymbol{R}_{b}=\sum_{i=1}^{N} f_{i} \boldsymbol{R}_{i, b}+\boldsymbol{e}_{b}$

where $R_{b}$ is the reflectance for a given band of sensor, $N$ is the number of endmembers, $f_{i}$ is the fraction of endmember $i$, $R_{i, b}$ is the reflectance of endmember $i$ in band $b$, and $e_{b}$ is the un-modeled residual. However, SMA fails to account for pixel-scale variability in spectral dimensionality, spectral degeneracy between materials and natural variation in the spectral of most materials [10]. Therefore this technique may not be appropriate in coastal regions where there is high percent of pixels confusion among sedimentary regions, bare lands and urban areas. Besides this, the morphology of Chinese cities are very dense and intermixed, thus these situation make difficulty for extracting impervious surfaces based on SMA.

Acknowledging these limitations, we developed HSMA algorithm to derive impervious surfaces from Landsat images over the coastal region of Hangzhou Bay. In this aspect, a range of masks were built before applying SMA to the Landsat images in order to purify urban regions. These masks includes, forest cover, agricultural land, sandy and sediment areas. The masks were separately constructed by using Maximum Likelihood classifier for each Landsat image.

After purifying process, urban regions were extracted from Landsat image. Then we assumed that urban regions composed of two endmembers including non-industrial(e.g., low density residential area and roads) and industrial(e.g., factory and airport) areas. Thus endmember fractions were computed by building a fully constrained two-endmember SMA using the purified Landsat ETM+ and TM reflectance data. Finally, impervious index was calculated by adding non-industrial and industrial fraction images. This index is between $0-1$ (or 0 to $100 \%$ ). In our research, high percent imperviousness index accounted for industrial regions( greater than 60\%). Non industrial areas showed low percent of this index( less than 60\%).

\section{RESULTS AND DISCUSSION}

The final impermeable maps for 1987, 2001 and 2009 are illustrated in Figure 2. Yellow colour represents low extreme and brown colour high extreme of impervious surface. Accordingly, this bay has witnessed rapid impervious surface growth between 2001 and 2009( during 8 years). From 1987 to 2001, the area of impervious surface reached to 49263 ha while it sharply increased by 88951.12 ha between 2001 and 2009. 


\section{A sequence of impervious surface growth over Hangzhou Bay}
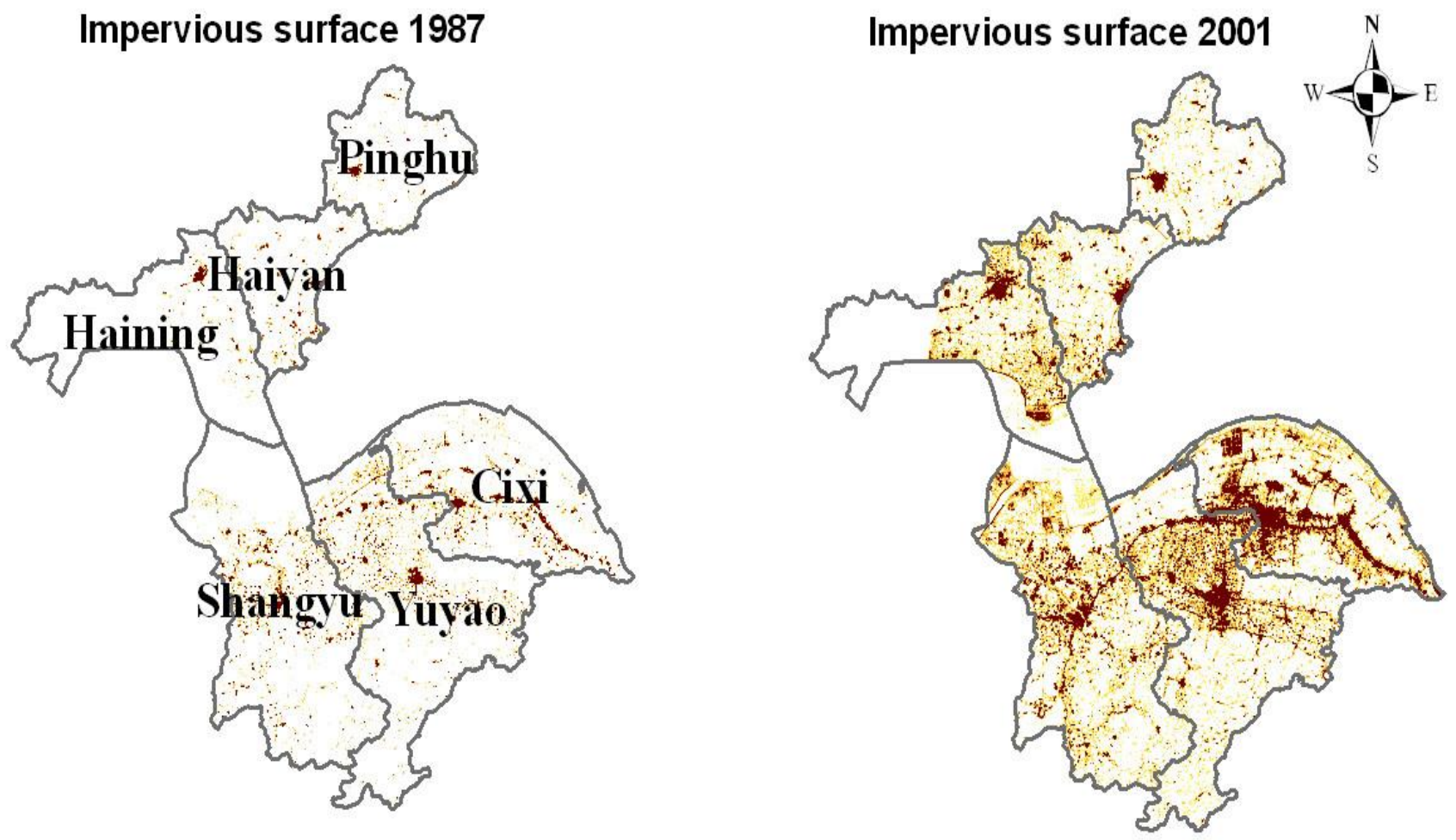

Impervious surface 2009

Legend

$\square$ county boundary

Impervious Surface(\%)

Value

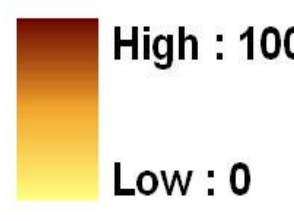

\section{0}

\section{Kilometers}

Figure 2, Impervious estimations For Hangzhou Bay and its six counties at three different years.

As shown in Figure 3 and Figure 4, it can be seen that tremendous impervious surface expansion (non-industrial and industrial) occurred in Cixi, Shangyu and Yuyao counties (south part of Hangzhou Bay). Take Cixi and
Pinghu counties in south and north of this Bay as an example, respectively. In Cixi County industrial areas expanded by 3200 ha in the period 1987-2001 and 13000ha from 2001 to 
2009. However, in Pinghu this class ascended by 420 ha and 3400 ha in the first and second period, respectively.

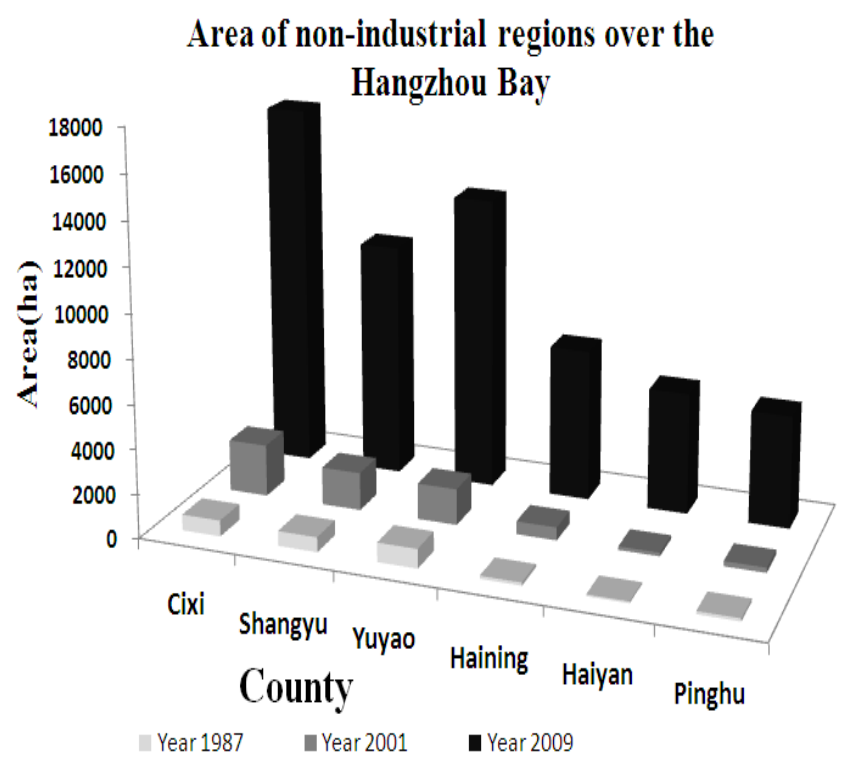

Figure 3 Change in non-industrial regions between 1987 and 2009.

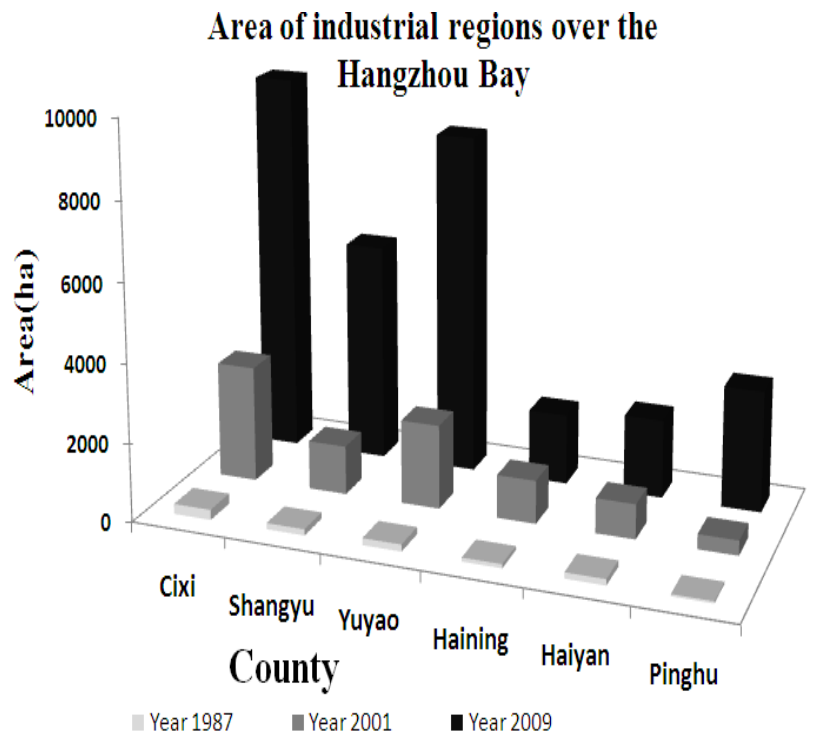

Figure 4 Change in industrial regions between 1987 and 2009

Two major reasons might support dramatic growth of impervious cover in the south of this bay, namely, economic growth and policy. In terms of the economy, since 1987 rapid economic development has achieved in the south of the bay through climbing Growth Domestic Product(GDP)(Figure 5). In fact the regions experiencing rapid economic development usually have large amount of land use changes( $\mathrm{Li}$ and Yeh, 2004).

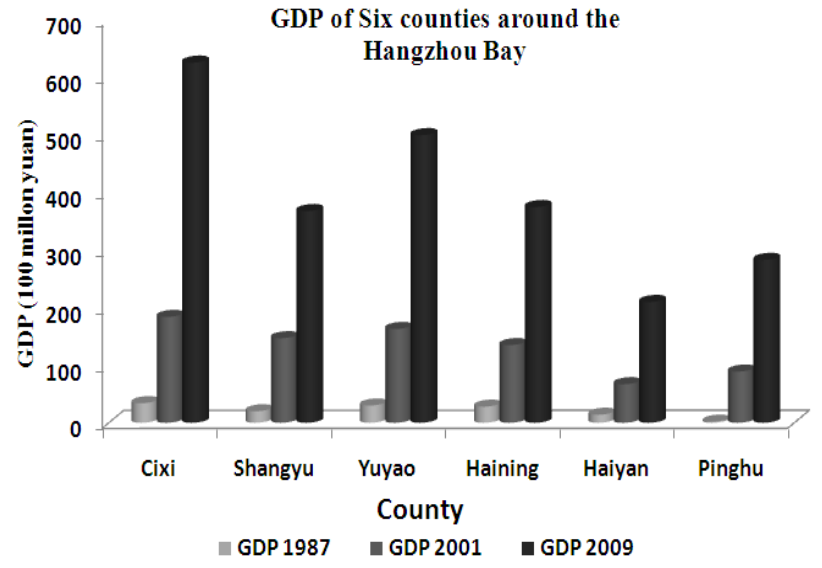

Figure 5, GDP of 6 counties around Hangzhou Bay

Another reason was policy. Some of the important policies in this regions was as follows: constructing Hangzhou Bay Bridge, speeding up constructions of express rail transportation between Shanghai, Hangzhou and Ningbo, advancing the planning and construction of Channel 2 on Shanghai-Hangzhou-Ningbo expressway, pushing forward the integrated construction of Ningbo-Zhoushan harbour basin and vigorously develop hi-tech industries and develop heavy and chemical industry in harbor areas [11].

However, apart from enhancing economic and urban development in the Hangzhou Bay, expansion of impervious surface could have induced a range of environmental problems. Our findings suggest that developing impervious surface caused most cities connected together, thus it generated a big impermeable land (Figure 2). Consequently, this surface may contribute to increasing pollution, lans surface temperature and environment impairment. For example, Ren et al., showed that rapid urbanization has already tremendously shrunk the size of the wetlands around the Hangzhou Bay[12]. They also demonstrated that according to present planning, construction lands will expand rapidly in the coming 15 years and will occupy many wetland areas, most of which are distributed in the south of this bay, for example, Cixi County.

\section{CONCLUSION}

In this study impervious surface analysis was employed to monitor urban growth around the Hangzhou Bay. In this regard, we first developed HSMA technique to cope with mixed pixels problem around this bay. Then impervious surface was derived from each Landsat data by this method. The result revealed that impermeable lands grew sharply ( in terms of area and percent) around the bay particularly in the south part between 2001 and 2009. In addition, our findings indicated that most lands connected together through expansion of impervious surface. As aforementioned, there is a link between impervious surface and ecosystem impairment. In this aspect expansion of impervious surface has already affect area of wetland around the Hangzhou Bay. However, more research is required to reveal other impacts of impervious surface expansion. 


\section{REFERENCE}

[1] Q.Weng, Modeling urban growth effect on surface runoff with the integration of remote sensing and GIS, Environment Management,Vo.28,No.6,2001,pp. 737-748 .

[2] H.Long, G.K. Heiling, X. Li, M. Zhang, Socio-economic development and land-use change: Analysis of rural housing land transition in the Transect of the Yangtse River, China, Land Use Policy, Vo.24, No.1, 2007,pp.141-153.

[3] S.L. Lu, X.H. Shen, L.J. Zou, Land cover change in Ningbo and its surrounding area of Zhejiang Province, 1987 2000. Journal of Zhejiang University-SCIENCE A, Vol.7, No.4, 2006, pp. 633-640

[4] H.Ding, , R.C. Wang, J.P. Wu,B. Zhou, Z. Shi, L.X Ding, 2007, Quantifying land use change in Zhejiang coastal region, China using multi-temporal Landsat TM/ETM+ images, Pedosphere, Vol.17, No. 6, 2007, pp. 712-720.

[5] T. Esch, V. Himmler, G. Schorcht, M. Thiel, T. Wehrmann, F. Bachofer, C. Conrad, Large-area assessment of impervious surface based on integrated analysis of single-date Landsat-7 images and geospatial vector data, Remote Sensing of Environment ,Vol.113,No.8, 2009, pp. 1678-1690.

[6] X. Yang, Z. Liu, Use of satellite-derived landscape imperviousness index to characterize urban spatial growth. Computer, Environment, Urban Systems, Vol.29, No. 5, 2005, pp.524-540.

[7] C.L. Arnold, C.J. Gibbons, .Impervious surface coverage: the emergence of a key environmental indicator, Journal of the American Planning Association,Vol. 62,No.2,1996,pp. 1996243 258.

[8] D. Lu, Q. Weng,. Use of impervious surface in urban land-use classification. Remote Sensing of Environment. Vol.102,No.12,2006,pp.146-160.

[9] R.L. Powell, D.A. Roberts, P.E. Dennison, L.L. Hess, ,. Sub-pixel mapping of urban land cover using multiple endmember spectral mixture analysis: Manaus, Brazil. Remote Sensing of Environment Vol.106,No.2,2007,pp. 2007253-267.

[10] D. Roberts, K. Halligan, P. Dennison, VIPER Tools User Manual, Version 1.2, 2007,www.vipertools.org (Access online: 4 April 2011)

[11] http://www.zhejiang.gov.cn (Access 20 May 2011)

[12] L. Ren, W. Yue, J. Li, C. Wu,. Impact of economic development on wetlands in Hangzhou Bay Industrial Belt. Journal. Geography of Science Vol.20,No.3, 2010,pp. 406-416. 